or treatment resistance which may be improved by the subsequently introduced Care Programme Approach. Perhaps a prospective randomised trial of discharge with or without s17 would assist in confirming the reasons for a fall in the numbers of patients recalled.

\section{References}

CHiswick, D. (1993) Compulsory treatment in the community in Scotland: ten questions and answers. Psychiatric Bulletin, 17, 424-425.

HAMPSON. S. \& DAVISON, P. (1994) Proposed new legislation for the care of mentally ill people in the community. Psychiatric Bulletin, 18, 726-729.

MOATE, T., Ward, B. \& EVANS, G. (1993) A community treatment order in practice. Psychiatric Bulletin. 17. 585-586.
PEASE, R. D. B. \& REED, J. (1993) Legal Powers on the Care of Mentally II People in the Community: Report of the Internal Review. London: Department of Health.

Pierides. M. \& CASEY, C. (1993) A community treatment order (letter). Psychiatric Bulletin, 17, 300.

ROYAL COLLEG OF PSYCHIATRISTS (1993) Community Supervision Orders, Council Report CR18. London: Royal College of Psychiatrists.

SENSKY, T.. HuGhes, T. \& HIRSCH, S. (1991) Compulsory psychiatric treatment in the community. Parts I and II. British Journal of Psychiatry. 158, 792-799: 799-804.

SYMONDS, R. L. (1993) Guardianship - a case for wider use. Psychiatric Bulletin, 17, 276-278.

TURNER. T. (1994) Compulsory treatment in the community: some debating issues. Psychiatric Bulletin, 18. 657659.

John Milton, Senior Registrar, Nottingham Healthcare NHS Trust, Porchester Road, Nottingham NG3 6AA

\title{
Supervised discharge order: the first year in the South and West Region
}

\author{
Anna Knight, David Mumford and Bob Nichol
}

\begin{abstract}
Information was collected from responsible medical ofilicers (RMOS) in the South and West Region who hod used the new supervised discharge order (SDO) (Section 25a) during the first year of its operation. Twenty-nine patients were placed on a SDO by 19 consultants. Most patients suffered from schizophrenla. In a third of cases, modication was stipulated as a requirement, atthough this is not legally permiselble. RMOs commented on the time-consuming process of applying for a SDO and felt it had limitted value because of the lack of sanctions.
\end{abstract}

The Mental Health Act of 1983 is concerned exclusively with hospital-based assessment and treatment of patients suffering from psychiatric disorders. Since the Act, there has been a continuing shift in psychiatric practice towards community-based treatment, and this combined with the growing public concerns about a small number of highly publicised dangerous patients has been the impetus to further legislation.

On the 1 April 1996, the Mental Health (Patients in the Community) Act 1995 came into operation. The principal provision of this new Act was the supervised discharge order (SDO: Section 25a), which aims to ensure that patients discharged from Section 3 or Section 37 receive appropriate aftercare. A patient can be required to (a) live at a specified address, (b) allow access to the supervisor and other professionals and (c) to attend for specified treatment.

The aim of this project was to quantify the use of these new provisions in the South and West Region; determine the characteristics of patients placed on a SDO; and explore the experience of psychiatrists who have used the new powers in the first year. 


\section{The study}

Regular telephone enquiries were made to the 35 Mental Health Act administrators of the hospitals and trusts in the South and West Region. When a supervised discharge order was being used, the name of the responsible medical officer (RMO) was requested and an appointment made to interview them. This was a semi-structured interview, covering the history of the patient concerned, the RMO's experiences of the new legislation and comments about its usefulness.

\section{Findings}

On the basis of telephone enquiries there were 29 supervised discharge orders implemented during the first year in the South and West Region. These involved 19 consultant psychiatrists; we interviewed all of them (or their locums). Three consultants had three patients each on a SDO; four had two patients each and the rest had one patient. These were widely spread across the South and West Region in both urban and rural areas.

The characteristics of patients are given in Table 1. There was a small preponderance of males. The average age of the patients was 42 years (range 25-76 years). The most frequent primary diagnosis was schizophrenia; substance

Table 1. Characteristics of patients and supervised discharge orders $(n=29)$

\begin{tabular}{lc}
\hline & $n(\%)$ \\
\hline Gender & $16(55)$ \\
Male & $13(45)$ \\
Female & \\
Ethnicity & $25(86)$ \\
White & $3(10)$ \\
African-Caribbean & $1(3)$ \\
Mixed race & \\
Diagnosis & $23(79)$ \\
Schizophrenia & $4(14)$ \\
Manic depression & $1(3)$ \\
Personality disorder & $1(3)$ \\
Anorexia nervosa & \\
Previous section & $27(93)$ \\
Section 3 & $2(7)$ \\
Section 37 & \\
Supervisor & $14(48)$ \\
Social worker & $10(35)$ \\
Community psychiatric nurse & $2(7)$ \\
Consultant psychiatrist & $18(62)$ \\
Residence requirement - yes & $28(97)$ \\
Attendance requirement - yes & $20(69)$ \\
Access requirement - yes & \\
\hline
\end{tabular}

misuse was an additional diagnosis in four cases. One patient had mental impairment with a history of sexual offending. Thirteen of the patients $(45 \%)$ were deemed to be a risk to others. The 'requirements' stipulated in the SDOs are summarised in Table 1 . In 14 cases $(48 \%)$ all three requirements were stipulated and in 10 cases, two requirements. In all but one SDO, the patient was required to attend for treatment. Where the requirement was to live in a hostel, access was often not stipulated but may have been assumed. In 10 cases (35\%) there was a stipulation on the SDO form to accept medication (although this is not legally permissible). The supervisor was most frequently a social worker or community psychiatric nurse. In all cases the community RMO was the same individual as the RMO.

RMOs were asked who had prompted the idea of a supervised discharge order. In the majority of cases $(76 \%)$ it had been their own idea, but in two instances it had been prompted by a mental health review tribunal and in four cases by social workers. In one case, a patient with frequent relapses of mania, the SDO had been actively sought by the patient herself, as she perceived herself to be safer on the order.

As required by the Act, the consultation phase canvassing the views of family, patient and concerned professionals had been wide. On the whole, the general practitioners (GPs) involved were willing to go along with any proposed plans. However, in one case the GP refused to participate on the grounds that the patient was, in his opinion, too dangerous to be allowed out of hospital. The approved social workers concerned were more aware of the legislation and in several cases were the prime movers. This appeared to be particularly so where there had been some discussion of using guardianship as an alternative. Families generally appeared to be supportive. The patent's reaction to the proposal of a supervised discharge order was often one of relief, as it was seen as a method of getting out of hospital.

The RMOs were frequently sceptical about the practicalities of using the "power to convey", particularly where there was a perception that the local police would be unwilling to assist. However, in some rural areas the power to convey was thought to be helpful to enable a Mental Health Act assessment to occur at a more convenient place for the psychiatrist rather than at the patient's home.

\section{Comment}

As there is no central register of SDOs, and the Mental Health Act Commission is not involved, we had to devise our own method of quantifying 
their use. In general, the Mental Health Act administrators were very helpful and we believe that we have discovered the majority of cases. We found that the use of Section 25a was patchy across the region, in both urban and rural areas. As expected with any new legislation, there appear to be a few 'enthusiasts' and many RMOs who have not yet tried it. The 19 RMOs who used a SDO represent about $11 \%$ of consultant psychiatrists in the South and West Region.

The characteristics of the patients involved reflect those of the patients with severe mental illness found in general psychiatric practice with no obvious over-representation as regards age or gender. There appeared to be three broad groups of patients where the RMOs expressed greatest optimism for success. The first group comprised of those patients who are generally not compliant but were basically law abiding individuals who would cooperate when awed by the weight of law, even when no sanctions would be taken if they should break the requirements. The second group comprised those where a requirement to live in a suitable place, particularly a hostel, was deemed an important part of that patient's community care. The third group comprised those who mistakenly believe that if they did not cooperate with medication they would be admitted to hospital.

It was surprising that in so many cases medication was stipulated when it has been explicitly excluded from the Act. The Royal College of Psychiatrists had previously advocated a community treatment order, and recommended that treatment should be included in the SDO, and it appears that some psychiatrists have mistakenly assumed that this is the case. It is a matter of concern that patients are complying with medication under such duress.

The majority of RMOs commented on the timeconsuming process of filling in the relevant forms. In particular it was noted that unlike other parts of the Mental Health Act, the RMO acts as the applicant and therefore should not strictly complete their part of the form until he has received the recommendations. This can be difficult as frequently the social worker and GP making the recommendations wish to see what the psychiatrist has written first. This problem can be overcome by the psychiatrist completing his part of the form but not signing and dating it until he or she has received the two recommendations.

There was a wide variety in the readiness with which the health authority had appointed an administrator to receive the forms. In some areas there appeared to be some reluctance and hesitation to do this. Further difficulties were encountered when a key member of staff was absent at a crucial time prior to the lapse of Section 3 or 37 . It was pointed out that consideration of a SDO therefore should occur at the earliest possible opportunity.

The attitude of many of the psychiatrists interviewed was that "it was worth a try" and that there were potential benefits in tightening up on procedures that should be occurring anyway. However, after a first experience several commented that the potential advantages were outweighed by the extra time involved. In contrast a few others felt that as their confidence and experience of this legislation grew that it could be useful in certain selected cases. A few psychiatrists expressed anxiety that, if these patients misbehaved or things went wrong, more blame could be attached to them. There was concern that if the patient reoffended, readmission to hospital would be assumed rather than bringing charges against the individual.

Even those psychiatrists who had experience of using a supervised discharge order had areas of confusion or gaps in their knowledge. In one case the psychiatrist was told that the GP could not complete his recommendation because he was not Section 12 approved, and therefore it was completed by a consultant colleague. There was also uncertainty as to whether an approved social worker completing the recommendation could also act as a supervisor and in some cases this was purposefully avoided by involving a second social worker.

When asked how they would change this piece of legislation, the majority of RMOs expressed the need for some form of community treatment order. Some felt that a Section 25a should be more akin to Section 17 leave (i.e. a requirement for treatment with easier readmission). An alternative idea was that in addition to a power to convey there should be a power for in-patient assessment (i.e. a week or so as part of the mental health assessment). Another suggestion was that the Section 25 a could be converted to a Section 3 on the signature of the RMO alone.

Anna C. Knight, Senior Registrar, Fromeside Unit, Blackberry Hill Hospital, Bristol; "David B. Mumford, Consultant Senior Lecturer, Division of Psychiatry, Department of Clinical Medicine, University of Bristol, 41 St Michael's Hill, Bristol BS2 8DZ; and Robert Nichol, Mental Health Act Commissioner/Approved Social Worker, Tetbury. Gloucestershire

*Correspondence 